\title{
Teaching Students with Low Academic Achievement in Reading Through Multisensory Approach - Intervention Programme
}

\author{
Sheikha Rashid Al-Shabibi ${ }^{1 *}$, Mariam Khalfan Al-Shaqsi ${ }^{1}$
}

${ }^{1}$ Ministry of Education, Batina South Directorate, Human Resources Department, OMAN
${ }^{*}$ Corresponding Author: shiekha_shabibi@hotmail.com

Citation: Al-Shabibi, S. R., \& Al-Shaqsi, M. K. (2019). Teaching Students with Low Academic Achievement in Reading Through Multisensory Approach - Intervention Programme. Mediterranean Journal of Social \& Behavioral Research, 3(1), 3-7. https://doi.org/10.30935/mjosbr/9587

\begin{abstract}
Jolly Phonics is a multisensory approachdesigned to teach children how to read, write and spell using a systematic multisensory phonics program. It uses synthetic phonics method. In this programme children learn the letter sounds first and then move on to blending [putting together] the sounds in order to read words. Jolly Phonics was developed for children from junior kindergarten to grade 2. It can be used for children who have reading/ writing difficulties. The researchers have noticed, while working as supervisors in Cycle One Omani schools, that grade threestudents have certain weaknesses in reading. They realized that some students could not even read simple words though they have spent 2 years and a halfstudying English.In order to investigate this problem, six low achievers students from grade 3 were selected; they were males and females and their age is between 8-9 years old. A certain scheme was designed; it included teaching one lesson a week for 4 months using Jolly Phonics programme. The teacher was provided by the Jolly Phonics materials to help her teaching the lessons effectively. The programme included learning the letter sounds, learning the letter formation, blending, identifying sounds in words and spelling the tricky words. A certain exam has been given to the students before and after the programme. The results show that there is a noticeable improvement in the students' academic achievement comparing with their previous level. The presentation will be interactive, researcher and audience together will explore to what extent this programme has certain effectiveness on students' performance. Findings will be set beside those from previous studies, implications for the Omani classroom will be discussed, and recommendations made for future research. Excerpts from students reading and writing will be shared with the audience.
\end{abstract}

Keywords: teaching low achievers, multisensory approach, intervention programme

Received: 7 Nov. 2018 Revised: 15 Feb. 2019 • Accepted: 12 Mar. 2019

\section{INTRODUCTION}

Multi-Sensory approach teaches reading and writing through using auditory, visual and kinesthetic pathways; it is diagnostic as it involves constant testing and reflection on the knowledge of the student (AlMamari, 2012). It is systematic and seeks to unite the components of written language. Thus, it treats sound-symbol knowledge, oral language (grammar and pronunciation), written language conventions and handwriting in an organised and integrated ways (Steward, 2011). The researchers have noticed, while working as supervisors in Cycle One Omani schools, that grade three students have certain weaknesses in reading. They realized that some students could not even read simple words though they have spent 2 years and a half studying" English For Me" syllabus. As supervisors, they believe in a developmental approach to teaching literacy skills. Therefore, they utilize an intervention programe based on jolly phonic approach as it is a multi-sensory approach to teach children the sounds of the English language and their alphabetic representations. Each sound is taught through a story with a picture clue and motion to help students remember the sound. Jolly Phonics is a programme designed to teach children how to read, write and spell using a systematic multisensory phonics program. It uses synthetic phonics method. In this programme children learn the letter sounds first and then move on to blending [putting together] the sounds in order to read words. Jolly Phonics was developed for children from junior kindergarten to grade 2 and it can be used for children who have reading and writing difficulties (Al-Mamari, 2012).

\section{LOW ACADEMIC ACHIEVEMENT IN READING}

Reading is central to the learning process. It is considered as one of the most difficult tasks of a language teacher to foster. Unfortunately, due to time limits and other constraints, teachers are often unable to actively encourage children to approach, Latha (2005). Thus, many students still face serious difficulties in reading and always seek for help from teachers. In Omani context students who are suffering from 
reading difficulties, as characterized by Al Humidi (2009), are those who have very basic grapho-phonemic knowledge which allow them to sound some (but not all) of the words. Their syntactic knowledge, though, seem limited and they are not able, for example, to use morphological clues to work out the meanings of words. Their vocabulary is very limited, and thus they rely largely on pictorial clues in interpreting the text. Their ability of reading on the whole is very slow and they are very hesitant and lack confidence.

\section{REVIEW OF RELEVANT STUDIES}

In 2004, Watson \& Johnston conducted a study that offered support for synthetic phonics applied for 3 groups. One group received an analytic phonics programme, the second group received the same programme plus phonological awareness training and the third group was taught using a synthetic phonics method. The intervention programme was 20 minutes a day and lasted for 16 school weeks after which the participants were post -tested.It was found that the synthetic phonics method group had better reading, spelling and phonemic awareness than the other 2 groups that were taught by analytic phonics.

Dalgren\&Boulware- Gooden (2002) conducted a study to examine the efficacy of a multisensory teaching approach to improve reading skills at the first-grade level. The control group was taught by Houghton-Mifflin Basal Reading programme while the treatment group was taught by the Language Basics which incorporates the Orton- Gillingham-based Alphabetics Phonics Methods. The OrtonGillingham, similar to the jolly phonics, is a multisensory method of teaching language related skills that focuses on the use of sounds, syllables, words, sentences and written discourse. The results showed that the treatment groups made statistically significant gains in phonological awareness, decoding and reading comprehension while the control group made gains only on reading comprehension.

Stewart (2011), in a qusai- experimental study, investigated whether first grade struggling readers, those who score below the $30^{\text {th }}$ percentile, will make greater progress in decoding skills with phonics instruction that is based on a highly systematic and multisensory instructional approach than struggling readers using a traditional design. The experimental group received multisensory instructions through direct teaching of synthetic sequential phonics using OrtonGillingham approach while the control group received phonics instructions using a traditional basal reading approach. Pretest and posttest scores measured progress on word attack and word identification. Data analyses using t-test results support that direct instruction using systematic, multisensory, synthetic phonics techniques significantly increased the decoding skills of readers.

Al-Mamari (2012) conducted a quasi- experimental study to investigate the effectiveness of integrating synthetic phonics instruction on developing early reading skills (namely phonics identification, phonemic awareness and word reading skills). The study also compared students' performance in early reading skills with the minimum required level set by the Ministry of Education in Oman. Two intact classes comprising fifty grade one Omani students from Yanabi-Al-Hikma School in Batinah South Governorate participated in the study. One class, the experimental class was taught using a commercially synthetic program called Jolly-Phonics while the control class was taught using the traditional method of whole word reading. Both groups were pretested on measures of phonics identification, phonemic awareness and word reading prior to the 9- week intervention using either the experimental or control method. Then students were post-tested on all measures immediately after intervention. Data analyses using t-test results support that direct instruction using synthetic phonics techniques significantly increased phonics identification, phonemic awareness and word reading skills of readers.

\section{THE PURPOSE OF THE PROGRAMME}

In Oman, the English language is considered as a foreign language for Omani students studying in government schools. Students in Oman start learning English from grade one and they take seven weekly lessons of 45 minutes long in the first four grades. Despite the great emphasis in developing reading skills, we have noticed as supervisors that most students in cycle one schools still encounter difficulties in reading. According to our observations, we have noticed that studentssee words as whole patterns and, therefore, memorize the look of words and learn to associate the printed word with meaning which is the Omani developed "English For Me" syllabus is based on. We have experienced that 4 out of 30 students in grade 3 could not even read simple words or recognize simple letters. Based on that, the current intervention programme investigates the effect of integrating multisensory approach within the "English For Me" syllabus for grade 3 low achievers.

\section{THE METHOD}

In order to investigate this problem, six students who have serious weaknesses in reading were selected. They are in grade 3 from Ashuaiba (1-4) school; they were 4 boys and 2 girls, and their age is between $8-10$ years old. The six students have been selected from different academic and social back grounds. These students have been chosen on specific criteria including previous academic performance (continuous assessment records), teachers' daily observations, students' portfolios and pre-test. The students have been taught by Wafa Al Nofli, who is one of the best and well qualified teachers in A'shuaiba school. A certain scheme was designed; it included teaching one lesson a week for 3 months using multi- sensory Jolly Phonics programme after which the students were post-tested. The teacher was provided by the Jolly Phonics materials to help her teaching the lessons effectively. The programme included learning the letter sounds, learning the letter formation, blending, identifying sounds in words and spelling the tricky words. A certain exam has been given to the students before and after the programme.

\section{RESULTS AND DISCUSSIONS}

The students have shown good improvement in reading letters and simple words as it is clearly shown in Table 2 of post test scores. The improvement shown by the students in reading skills could be attributedto the Jolly phonics programme which has implemented with the targeted group. The programmeemphasizes the teaching of phonics, word reading and phonemic awareness. The findings match previous researches that investigated the effectiveness of synthetic phonics in settings where English is spoken as a first language (Watson 
Table 1. Pre test scores

\begin{tabular}{|c|c|c|c|c|c|c|c|c|c|}
\hline \multirow{3}{*}{ No } & \multirow{3}{*}{ Name } & \multirow{3}{*}{ Class } & \multicolumn{6}{|c|}{ Pre test } & \multirow{3}{*}{$\begin{array}{c}\text { Total score of } \\
\text { correct } \\
\text { responses } \\
\end{array}$} \\
\hline & & & \multicolumn{3}{|c|}{ Letters } & \multicolumn{3}{|c|}{ Words } & \\
\hline & & & Correct & Incorrect & NR & Correct & Incorrect & NR & \\
\hline 1 & Yaqeen Al Shabibi & $3 / 1$ & 11 & 7 & 8 & 3 & 18 & 5 & 14 \\
\hline 3 & Mohammed Al Hanai & $3 / 3$ & 11 & 12 & 3 & 0 & 23 & 3 & 11 \\
\hline 4 & Waleed Al Shiryani & $3 / 4$ & 6 & 5 & 15 & 3 & 23 & 0 & 9 \\
\hline 5 & Mishari Al Beloushi & $3 / 4$ & 7 & 19 & 0 & 0 & 26 & 0 & 7 \\
\hline
\end{tabular}

Table 2. Post test scores

\begin{tabular}{|c|c|c|c|c|c|c|c|c|c|}
\hline \multirow{3}{*}{ No } & \multirow{3}{*}{ Name } & \multirow{3}{*}{ Class } & \multicolumn{6}{|c|}{ Post test } & \multirow{3}{*}{$\begin{array}{c}\text { Total score of } \\
\text { correct } \\
\text { responses }\end{array}$} \\
\hline & & & \multicolumn{3}{|c|}{ Letters } & \multicolumn{3}{|c|}{ Words } & \\
\hline & & & Correct & Incorrect & NR & Correct & Incorrect & NR & \\
\hline 1 & Yaqeen Al Shabibi & $3 / 1$ & 22 & 4 & 0 & 22 & 4 & 0 & 44 \\
\hline 2 & Aysha Al Nofli & $3 / 2$ & \multicolumn{7}{|c|}{ Transferred } \\
\hline 3 & Mohammed Al Hanai & $3 / 3$ & 16 & 7 & 2 & 16 & 9 & 1 & 32 \\
\hline 4 & Waleed Al Shiryani & $3 / 4$ & 16 & 8 & 3 & 15 & 11 & 0 & 31 \\
\hline 5 & Mishari Al Beloushi & $3 / 4$ & 20 & 4 & 2 & 14 & 12 & 0 & 34 \\
\hline 6 & Ammar Al Jabri & $3 / 3$ & 25 & 1 & 0 & 25 & 1 & 0 & 50 \\
\hline
\end{tabular}

\& Johnston, 2004; Boulware- Gooden, 2002; Stewart, 2011). Besides, improvement made by students in phonics identification could be referred to some elements found in synthetic phonics instruction in addition to some other elements unique to Jolly Phonics. For example, phonics teaching is multisensory and is done using all learning pathways in the brain (Kinesthetic, visual, auditory and tactile) which enhances memory and learning, Al-Mamari (2012).

It has been noticed that students have enjoyed learning using the multisensory approach (Jolly Phonics programme) because, according to the scheme, for each letter introduced there is a story, a simple song and an action reflecting an event in the story. Added to this, there is also simulating picture within the programme (including big books, flash cards and visual cards) that enhance students recall of these phonics. Moreover, students maintain workbooks that contain pictures illustrating the actions for each letter which help students to remind them of the actions and accordingly the corresponding letters. It is worth mentioning that the students' families have played a vital role in upgrading the students' level. Being in contact with the students' families, via what's' up group, paved the road for the teacher to follow up her students successfully. Gutman \& McLovd (2000) have stated thatparents, as managers of their children's environments, not only create learning environments within the home but also encourage, organize, and supervise their children's educational opportunities in the community.

Some other factors have an influence on the targeted low achievers ability to improve their reading skill in this programme as summarized by Pressley \& Hilden (2006). Theyproposed that not only knowledge and use of learning strategies are essential for learning and achievement but that various individual characteristics of learners influence their ability to be self-regulated and to act successfully during learning; some of these are prior achievement, domain-specific knowledge, performance and regulation strategies and cognitive motivational differences. Moreover, another factor that affects the students' ability to improve rapidly is students' engagement and participation with the teacher in the lessons which makes them more confident and eager to learn. Hall (1984)has stated that students' engagement with active responding or opportunity to respond is a key factor in any academic achievement programmefor students who face difficulties in reading,

\section{TEACHER'S FEEDBACK UPON THE TARGETED GROUP PERFORMANCE}

The teacher has played a significant role to improve the students' performance in reading. The teacher has established good rapport with the students; for example, she is very patient, flexible, funny as well as cooperative. She was very keen to analyze her students' personality and she was a very good observer of their gradual academic progress.

The teacher maintains an organized and accurate field notes upon each student's performance based on her daily observation. Accordingly, she has noted that the whole students enjoyed learning the sounds with actions. She mentioned that the enthusiastic learning environment including songs, tactile activities, flash cards and using big book for story demonstration has promoted students to participate willingly in the programme. Besides, the small number of the students (six students only) as well as using various teaching techniques has encouraged them to be more confident and willing to share with their classmates. Also, what helps the students to improve rapidly that they have been chosen from the same academic standard (Low achievers); therefore, they have felt more independent and comfortable to learn together and correct each other's mistakes.

\section{SAMPLES OF THE TEACHER'S COMMENTS UPON EACH INDIVIDUAL STUDENT}

Al Yaqeen was very shy and she remains shy till the end of the programme. She wasn't that much initiative and always afraid to participate. Her parents are old and no one could help her at home. She prefers working in group rather than individually. At the end of the programme she has shown great improvement; in instance, the total score of her performance in the pretest is 14, while the total score of her post-test is 44.

Aysha was the best in the pre-test as seen in Table1. She was quite and that might due to her parents' divorce. She could recognize sounds easily but she couldn't read words. She is very quite but she is willing to participate in the written activities. I have noticed good improvement in reading words consisting 
of three sounds. She is good in blending and her performance in the tactile activities was amazing. Unfortunately, Aysha couldn't conduct the post test due to her family circumstances.

Mohammed missed some lessons because his mother seems to be busy. At the beginning wasn't able to recognize sounds or words and that has been evident from his pre- test score (11). His low performance might due to the private school that he spent 2 years in. Gradually, Mohammed has shown good improvement in reading words and that was clearly seen in his post-test (31).

Al Waleed was very moody and very dependent on his father. He is suffering from serious disease. He has the ability to read and write but he got bored easily. He has shown great improvement; in instance, the total score of his performance in the pre-test is 9, while the total score of his post-test is 31.

Mishari is the only child in his family. He is willing to participate with his classmates and his handwriting is very neat. He is a very well-organized student among his classmates. His low performance at the beginning of the programme might due to lack of parents' follow up. He has shown great improvement; in instance, the total score of his performance in the pre-test is 7 , while the total score of his post-test is 34 .

Ammar has suffered from some family problems and that affected his academic performance at the beginning of the programme. Gradually, he has gained some confidence from his teacher and his classmates. He seems to be very interested in the programme thus he was the best among his group. He has shown great improvement; in instance, the total score of his performance in the pre-test is 28 , while the total score of his post-test is 50 .

\section{DIFFICULTIES OF IMPLEMENTING THE PROGRAMME}

- Lack of collaboration from the part of school administration in setting up the schedule of the programme.

- The timing of the programme is not suitable for both the teacher and the students.

- The scheme is too detailed and needs some amendments regarding the content; for example, more time is needed for teaching'tricky words' and 'diagraphs'. Besides, teaching five individual sounds is beyond the students' ability.

- Shortages of instructional materials.

- Lack of cooperation from the part of students' parents.

\section{RECOMMENDATIONS}

- This type of intervention programme should be conducted from the beginning of the year.

- The materials should be prepared in advance, therefore, the concerned teacher will be able to run the programme earlier.

- A meeting with parents should be conducted prior to the programme implementation.

- Clear instructions concerning conducting pre and post tests should be stated and discussed with the concerned teacher from the beginning of the year.

- Such programme will be of great benefit for low achievers, as they are usually highly neglected by their teachers in the normal lessons. On this basis, schools should integrate such intervention programme to the whole low achievers in the school. This can be included in the school annual plan.

To conclude, the study identified certain areas that need attention Firstly, it suggests that a new assessment tool needs to be developed to identify those who need such intervention programmes. Secondly, closer collaboration between teachers, parents, students and other professionals could strengthen the diagnosis process, which could see the structured use of observations. Thirdly, teachers, parents and students themselves should be more systematically involved in sharing knowledge, experience and skills in order to help students with low academic achievement in reading. Finally, the study suggests a strategy needs to be developed that will enable support to be provided for all students who have certain weaknesses in reading, that is, such students to be under focus while teaching takes place. It suggests a move towards inclusive classrooms and inclusive teaching, and the use of differentiated instruction and differentiated tasks that give all the opportunity to achieve, Al Ghafri (2009).

\section{REFERENCES}

Adams, M. J. (1990). Beginning to read: Thinking and learning about print. Cambridge, MA. MIT.

Al-Ghafri, S. (2009). The effectiveness of the Learning Difficulties Programme in Basic Education Cycle 1 schools. Ministry of Education. Sultanate of Oman.

Al-Mamari, F. (2012). Effect Synthetic Phonics Instruction on Early Reading Skills of Grade One Students in Oman. Published Master's Thesis, Sultan Qaboos University Oman.

Dahlgren, R., \& Boulware-Gooden, R. (2002). Teaching reading in an inner city school through a multisensory approach. Annals of Dyslexia, 52, 229-242.

Greenwood, C. R., Delquadri, J., \& Hall, R. V. (1984). Opportunity to respond and student academic performance. In W. L. Heward, T. E. Heron, J. Trapp-Paper, D. S. Hill (Eds.) Focus on behavior analysis in education. Columus. OH: Charles Merrill.

Gutman, L. \& McLovd, V. (2000). Parents' Management of their Children's Education within the Home, at School, and in the Community: An Examination of African-Amirican Families Living in Poverty. The Urban Review, 32, 1-24.

Johnston, R. \& Watson, J. (2004). Accelerating the development of reading, spelling and phonemic awareness skills in initial readers. Reading and Writing, 17(4), 327-357.

Latha, R. (2005). A Reading Programme for Elementary Schools. English Teaching Forum, 14(1), 18-23.

Lloyd, S. (1998). The Phonics Handbook. Essex, UK: Jolly Learning Ltd.

Mival, E. (1997). Using Jolly Phonics: A guide for teaching reading and writing. Essex, UK: Jolly Learning Ltd.

Pressley, M., \& Hilden, K. (2006). Cognitive strategies. In W. Damon \& R. M. Learner (Eds-in-Chief) \& R. Siegler (Vol. Eds), Handbook of Child Psychology: Vol.2.

Stewart, E. D. (2011). The impact of systematic multisensory phonics instructional design on the decoding skills of struggling readers. Walden University. ProQuest Dissertations and Theses. 


\section{Web Resources}

http://www.ehow.com/info_8742280_homemade-phonics-games https://www.wordsforlife.org.uk http://search.proquest.com/docview/225382153?accountid=27575

http://search.proquest.com/docview/856900916? accountid=27575

http://learninghelp.org.au/multi-sensory-approaches-to-teaching/

\section{$* * *$}

